\title{
Chromosomal segregation and fertility in Robertsonian chromosomal heterozygotes of the house musk shrew (Suncus murinus, Insectivora, Soricidae)
}

\author{
MARGARITA B. ROGATCHEVA $\dagger+$, SEN-ICHI ODA $†$, TATIANA I. AXENOVICH \\ YURII S. AULCHENKO $\$$, J EREMY B. SEARLE*§ \& PAVEL M. BORODIN \\ † Laboratory of Animal Management, School of Agricultural Sciences, Nagoya University, Nagoya 464-01, J apan, \\ $\$$ Institute of Cytology and Genetics, Novosibirsk 630090, Russia and §Department of Biology, University of York, \\ PO Box 373, York YO10 5YW, U.K.
}

Crucial to our understanding of chromosomal variation and evolution in mammals are detailed studies of chromosomal heterozygotes, with analyses of chromosomal segregation and chromosome-derived infertility. We studied segregation and fertility in hybrids between karyotypic races of the house musk shrew Suncus murinus. These individuals were heterozygous for up to five Robertsonian fusions (Rbs) and an insertion of heterochromatin in an autosome. All variant chromosomes showed Mendelian segregation and all Rbs segregated independently of each other in the progeny of double heterozygotes. Litter size in single and even multiple $\mathrm{Rb}$ heterozygotes was no smaller than that in the less fertile parental strain. The effects of genetic background were more important in determining litter size than Rb heterozygosity for the shrews that we examined.

Keywords: chromosomal segregation, fertility, Robertsonian fusion, shrew, Suncus murinus.

\section{Introduction}

One of most commonly observed chromosomal rearrangements in animals are Robertsonian fusions (Rbs), in which pairs of acrocentric chromosomes join at their centromeres to form single metacentric chromosomes. Rbs may occur sporadically (e.g. in humans: Boué \& Boué, 1981), as notable polymorphisms (e.g. in the grasshopper Dichroplus pratensis: Bidau et al., 1991) or fixed within populations in the case of $\mathrm{Rb}$ races (e.g. the house mouse: Sage et al., 1993). Persistence of an $\mathrm{Rb}$ in populations and whether it goes to fixation depend critically on whether the Rb chromosome confers some effect on viability or fertility and whether it is transmitted according to Mendelian expectation.

The aim of our study was to examine these factors in the house musk shrew Suncus murinus, a species which displays both $\mathrm{Rb}$ races and $\mathrm{Rb}$ polymorphisms. The house musk shrew is widely distributed throughout Asia and East Africa (Hutterer, 1993). Its standard karyotype consists of 40 chromosomes, 24 of which are acrocentrics. $\mathrm{Rb}$ variation has only been found in populations of musk shrews in Sri

*Correspondence. E-mail: jbs3@york.ac.uk
Lanka, southern India and the Malay peninsula (Sam et al., 1979; Yosida, 1982; Rogatcheva et al., 1997). To simulate the natural hybridization of two $\mathrm{Rb}$ races, two laboratory strains of shrews have been crossed. These are derived, respectively, from wild populations in Nepal (standard 40 chromosome karyotype) and Sri Lanka (30-34 chromosomes, with five pairs of $\mathrm{Rb}$ fusions, two of which are polymorphic). After several generations of backcrossing and intercrossing of hybrids, the $\mathrm{Rb}$ chromosomes have persisted in a hybrid stock (Rogatcheva et al., 1997).

We use shrews of this hybrid stock to analyse the segregation of the five Rbs in progeny of male and female heterozygotes and to estimate the influence of $\mathrm{Rb}$ heterozygosity on fertility.

\section{Materials and methods}

Shrews of the KAT and SRI laboratory strain and SK hybrid stock were used in this study. The KAT strain was derived from a wild population in Katmandu, Nepal and maintained as a close breeding colony for eight generations (Oda et al., 1992); it has the standard karyotype of 40 chromosomes (Rogatcheva et al., 1996). The SRI strain was 
derived from shrews originally captured in Sri Lanka (Ishikawa et al., 1989). The progenitors of the SRI strain had a 30-34 chromosome karyotype; they were homozygous for three $\operatorname{Rbs}(8.17,9.13,14.15)$ and polymorphic for two others $(10.12,11.16)$. Also, the SRI chromosome 7 carries a large insertion of heterochromatin (Rogatcheva et al., 1997). The SK hybrid stock was established by crossing individuals of the KAT and SRI strains; all $\mathrm{F}_{1} \mathrm{KAT} \times \mathrm{SRI}$ individuals and their descendants are defined as 'SK' shrews. In the stabilization of the SK stock, SRI $\times$ KAT hybrids were intercrossed or backcrossed to KAT or SRI over three generations; thereafter the stock was maintained by intercrossing SK individuals.

We karyotyped SK individuals of the third and fourth generations after stabilization of the stock. Chromosome preparations were made from fibroblast cultures established from tail-tip biopsies. G-banding was performed according to the method of Seabright (1971) as modified by Grafodatsky \& Radjabli (1988).

The karyotyped animals, which were heterozygous for one to five Rbs in various combinations and/or the SRI chromosome 7 variant, were then backcrossed to the KAT strain and intercrossed with each other. In the intercross pairs the male and female were both heterozygotes, but for different fusions. That allowed us to analyse the transmission of different Rbs via the SK male and the SK female at the same time. We also set up several pairs where males and females were heterozygous for the same fusions. Altogether 20 females and 18 males of the KAT strain and 48 females and 29 males of SK stock were crossed.

The litter size at birth and the sex ratio were scored for all crosses. Litter sizes in the SRI and KAT strains, and for all SK crosses made before and during our experiment, were extracted from the pedigree records. The pedigree records were also used to calculate the genetic contribution of the parental strains to hybrid individuals. We traced the ancestry of each hybrid individual back to the SRI and KAT progenitors. Assuming that every offspring receive half their genes from each parent, $F_{1}$ and $F_{2}$ hybrids are $50 \%$ SRI, first backcrosses to KAT are $25 \%$ SRI, etc.

\section{Results}

\section{Segregation}

Table 1 shows segregation of the five Rbs in all informative crosses. Altogether 290 offspring of 136 litters were karyotyped. Because many parents were heterozygous for several Rbs, their offspring provided information on segregation for more than one chromosome. Hence, the pooled number of informative offspring presented in Table 1 is higher than 290. The observed numbers of homozygous vs. heterozygous offspring for each of the five chromosome combinations were tested separately by $\chi^{2}$-tests for three groups of crosses: female heterozygotes $\times$ male acrocentric homozygotes, the reciprocal crosses and crosses between heterozygotes for the same chromosome.

None of the chromosomes in any type of cross showed a significant deviation from the expected ratio. The total and pooled distributions of offspring also did not differ from the expected distribution. The transmission ratio for each of the Rbs was very close to 0.5 (Table 1 ).

Table 2 presents the data on the segregation for the SRI chromosome 7 in reciprocal crosses of normal $(+/+)$ and heterozygous $(\mathrm{Is} /+)$ shrews. Both males and females transmitted the Is chromosome and its normal homologue in conformity with Mendelian expectation.

We tested the independence of segregation of different Rbs from double heterozygotes by $2 \times 2$ tables (Bliss, 1967). All pairs of autosomes that were tested showed independent segregation (Fig. 1).

We also assessed sex ratio in the informative crosses for each of the Rbs (Fig. 2). After application of the Bonferroni correction for multiple testing, there were no significant deviations from a normal 1:1 sex ratio among $\mathrm{Rb}$ and non-Rb progeny.

\section{Fertility}

To assess the effects of $\mathrm{Rb}$ heterozygosity on the litter size in S. murinus, we had to control for all other effects, such as year, season, parity and genetic background.

The data used in this analysis have been accumulated over several years, but this did not affect the homogeneity of the data. The distribution of litter size among years within crosses did not vary significantly and there was no significant variation according to month of birth. The females in our sample differed in the number of litters they produced but there was no difference in the size of these litters. Mean $( \pm$ SE) differences between first and second litters, second and third, third and fourth, fourth and fifth were: $-0.26 \pm 0.29 ; 0 \pm 0.38 ; 0.13 \pm 0.64$; and $-0.47 \pm 0.99$, respectively, and did not differ significantly from zero. An ANOVA was consistent with this result: variation in litter size between dams was 
higher than that within dams $\left(F_{147,271}=2.09\right.$; $P<0.001)$.

Table 3(a) provides litter sizes for a variety of crosses involving SRI, KAT and SK stock. The SRI strain had a litter size almost half the size of the KAT strain $\left(t_{395}=13.06, P<0.001\right)$. It is remarkable that the litter sizes in KAT $\times$ SRI and SRI $\times$ KAT crosses were significantly smaller than in pure-bred KAT and did not differ from that of the less fertile
SRI parent. In other words, mating with a SRI male reduced the fertility of KAT females down to that of the SRI female level. The $\mathrm{F}_{1} \times \mathrm{F}_{1}$ intercrosses also demonstrated low fertility and did not differ significantly from SRI $\times$ SRI crosses. The mean litter size in pooled reciprocal crosses $\mathrm{KAT} \times \mathrm{F}_{1}$ and $\mathrm{F}_{1} \times \mathrm{KAT}$ was of intermediate value and differed significantly from SRI $\times$ SRI $\left(t_{144}=4.07, P<0.001\right)$ and KAT $\times$ KAT $\left(t_{347}=5.14, P<0.001\right)$. It is worthwhile to note

Table 1 Segregation of Rbs in progeny of heterozygous shrews

\begin{tabular}{|c|c|c|c|c|c|c|c|c|c|}
\hline \multirow[b]{2}{*}{ Dam } & \multirow[b]{2}{*}{$N$} & \multirow[b]{2}{*}{ Sire } & \multirow[b]{2}{*}{$N$} & \multicolumn{3}{|c|}{ Progeny } & \multirow{2}{*}{$\begin{array}{l}\text { Transmission } \\
\text { of } \mathrm{Rb}(p)\end{array}$} & \multirow{2}{*}{$\begin{array}{l}95 \% \text { Confidence } \\
\text { interval }\end{array}$} & \multirow[b]{2}{*}{$\chi^{2}$ (d.f.) ${ }^{*}$} \\
\hline & & & & $\mathrm{Rb} / \mathrm{Rb}$ & $\mathrm{Rb} /+$ & $+1+$ & & & \\
\hline $\mathrm{Rb}(8.17) /+$ & 15 & $+1+$ & 15 & & 21 & 20 & 0.512 & $0.354<p<0.670$ & $0.02(1)$ \\
\hline $\mathrm{Rb}(9.13) /+$ & 16 & $+1+$ & 12 & & 24 & 24 & 0.500 & $0.354<p<0.645$ & $0.00(1)$ \\
\hline Rb (10.12)/+ & 10 & $+1+$ & 9 & & 16 & 19 & 0.457 & $0.287<p<0.627$ & $0.26(1)$ \\
\hline Rb (11.16)/ + & 17 & $+1+$ & 12 & & 30 & 29 & 0.508 & $0.378<p<0.639$ & $0.02(1)$ \\
\hline Rb (14.15)/+ & 10 & $+/+$ & 9 & & 15 & 15 & 0.500 & $0.313<p<0.686$ & $0.00(1)$ \\
\hline Pooled & & & & & 106 & 107 & 0.498 & $0.431<p<0.565$ & $0.00(1)$ \\
\hline Total & & & & & & & & & $0.30(5)$ \\
\hline Heterogeneity & & & & & & & & & $0.29(4)$ \\
\hline$+/+$ & 19 & $\mathrm{Rb}(8.17) /+$ & 12 & & 37 & 41 & 0.474 & $0.361<p<0.587$ & $0.21(1)$ \\
\hline$+1+$ & 12 & $\mathrm{Rb}(9.13) /+$ & 10 & & 34 & 43 & 0.442 & $0.328<p<0.555$ & $1.05(1)$ \\
\hline$+1+$ & 5 & $\mathrm{Rb}(10.12) /+$ & 3 & & 21 & 13 & 0.618 & $0.449<p<0.786$ & $0.88(1)$ \\
\hline$+1+$ & 5 & Rb (11.16)/+ & 4 & & 12 & 19 & 0.353 & $0.210<p<0.564$ & $1.58(1)$ \\
\hline$+1+$ & 19 & Rb (14.15)/+ & 15 & & 38 & 43 & 0.469 & $0.358<p<0.580$ & $0.31(1)$ \\
\hline Pooled & & & & & 142 & 159 & 0.472 & $0.415<p<0.528$ & $0.96(1)$ \\
\hline Total & & & & & & & & & $5.03(5)$ \\
\hline Heterogeneity & & & & & & & & & $4.08(4)$ \\
\hline $\mathrm{Rb}(8.17) /+$ & 8 & $\mathrm{Rb}(8.17) /+$ & 7 & 5 & 20 & 10 & 0.429 & $0.260<p<0.598$ & $2.14(2)$ \\
\hline $\mathrm{Rb}(9.13) /+$ & 9 & $\mathrm{Rb}(9.13) /+$ & 5 & 2 & 10 & 5 & 0.412 & $0.160<p<0.664$ & $1.59(2)$ \\
\hline $\mathrm{Rb}(11.16) /+$ & 3 & $\mathrm{Rb}(11.16) /+$ & 2 & 3 & 5 & 2 & 0.550 & $0.199<p<0.901$ & $0.20(2)$ \\
\hline Rb (14.15)/ + & 10 & $\mathrm{Rb}(14.15) /+$ & 7 & 6 & 15 & 11 & 0.422 & $0.245<p<0.598$ & $1.69(2)$ \\
\hline Pooled & & & & 16 & 50 & 28 & 0.436 & $0.335<p<0.637$ & $3.45(2)$ \\
\hline Total & & & & & & & & & $5.62(8)$ \\
\hline Heterogeneity & & & & & & & & & $2.50(6)$ \\
\hline
\end{tabular}

*All $\chi^{2}$ values are smaller than the critical values.

Table 2 Segregation of chromosome 7 in progeny of heterozygous shrews

\begin{tabular}{lcrrcccc}
\hline & & \multicolumn{2}{c}{ Progeny } & & \multicolumn{2}{c}{$95 \%$} \\
\cline { 3 - 4 } Dam & Sire & Is/ + & $+/+$ & $\begin{array}{c}\text { Transmission } \\
\text { of Is } /+(p)\end{array}$ & $\begin{array}{c}\text { Confidence } \\
\text { interval }\end{array}$ & $\chi^{2}$ (d.f.) \\
\hline Is/ + & $+/+$ & 9 & 8 & 0.529 & $0.274<p<0.785$ & $0.06(1)$ \\
$+/+$ & Is $/+$ & 18 & 17 & 0.514 & $0.344<p<0.685$ & $0.03(1)$ \\
Total & & 27 & 25 & 0.519 & $0.381<p<0.658$ & $0.08(1)$ \\
\hline
\end{tabular}


that there were regular although nonsignificant reciprocal differences in the $\mathrm{KAT} \times \mathrm{F}_{1} / \mathrm{F}_{1} \times \mathrm{KAT}$ and $\mathrm{KAT} \times \mathrm{SRI} / \mathrm{SRI} \times \mathrm{KAT}$ crosses. Litter size was larger when the mother was KAT. Thus, considering the crosses involving SRI, KAT and $F_{1}$ shrews there were three distinct group of means: (1) large litter size for the cross KAT $\times$ KAT only; (2) small litter size for all crosses with SRI and for the $F_{1} \times F_{1}$; (3) intermediate litter size for $\mathrm{F}_{1} \times \mathrm{KAT}$ and $\mathrm{KAT} \times \mathrm{F}_{1}$.

To estimate the effect of a particular $\mathrm{Rb}$ on the size of the litters produced by male or female heterozygotes we pooled the data for all litters available. Table 3(b) shows that the size of these litters was intermediate between that of the KAT and SRI strains. There was no significant variation in litter

\begin{tabular}{|c|c|c|c|c|c|c|c|c|c|c|}
\hline \multicolumn{2}{|c|}{ Chromosome } & \multicolumn{2}{|c|}{8.17} & \multicolumn{2}{|c|}{9.13} & \multicolumn{2}{|c|}{10.12} & \multicolumn{2}{|c|}{11.16} & 14.15 \\
\hline & & $\mathrm{Rb}$ & + & $\mathrm{Rb}$ & + & $\mathrm{Rb}$ & + & $\mathrm{Rb}$ & + & $\mathrm{Rb}+$ \\
\hline \multirow[t]{2}{*}{8.17} & $\mathrm{Rb}$ & & & & & & & 9 & & 56 \\
\hline & + & & & 5 & 5 & 5 & 3 & 4 & 8 & 102 \\
\hline \multirow[t]{2}{*}{9.13} & $\mathrm{Rb}$ & & & & & & & 6 & & 43 \\
\hline & + & 8 & 10 & & & & 1 & 4 & 4 & 20 \\
\hline \multirow[t]{2}{*}{10.12} & $\mathrm{Rb}$ & & & & & & & 7 & & $0 \quad 5$ \\
\hline & + & 5 & 3 & 4 & 4 & & & & 6 & 62 \\
\hline \multirow[t]{2}{*}{11.16} & $\mathrm{Rb}$ & 1 & & 4 & & & & & & 43 \\
\hline & + & 6 & 7 & 7 & 9 & 10 & 6 & & & $4 \quad 5$ \\
\hline \multirow[t]{2}{*}{14.15} & $\mathrm{Rb}$ & & & & 10 & & & 0 & & \\
\hline & + & 13 & 14 & 7 & 12 & 0 & 0 & & 2 & \\
\hline
\end{tabular}

Fig. 1 Test for independence of segregation of different Rbs in the progeny of double heterozygote shrews. The segregation in the progeny of female double heterozygotes is presented above the main diagonal, that of male double heterozygotes is present below the main diagonal. size according to which $\mathrm{Rb}$ is involved or whether the female or male parent was heterozygous. A one-way ANOVA shows that variation in litter size between Rbs was lower than that within Rbs ( $F_{4,153}=0.68$ for dams and $F_{4,150}=0.13$ for sires).

The individuals involved in the crosses, discussed above, were multiple rather than single heterozygotes. We found a significant correlation between the litter size and combined heterozygosity of both parents (number of Rbs for which the parents were heterozygous): $r_{\mathrm{s}}=-0.35$, d.f. $=103, P<0.001$. A similar correlation was found between the litter size and the genetic contribution of SRI in both parents: $r_{\mathrm{s}}=-0.32, \quad$ d.f. $=103, \quad P<0.001$. A correlation between combined heterozygosity and genetic contribution of SRI was very high: $r_{\mathrm{s}}=0.82$, d.f. $=103, P<0.001$. Multiple regression analysis suggests that the variation in litter size was mainly determined by variation in genetic contribution of SRI $\left(b=-0.29, t_{105}=2.13, P=0.035\right)$. The effect of heterozygosity is apparently less important $\left(b=-0.09, t_{105}=0.66, P=0.509\right)$.

\section{Discussion}

Animals that are heterozygous for Rbs might be expected to have reduced fertility relative to homozygotes, because of aberrant pairing at prophase I (resulting in germ cell death) and malsegregation at anaphase I (resulting in aneuploidy and consequent embryonic losses). The extent of the reduction in fertility depends on the species involved, the number of the heterozygous Rbs, the genetic background in which they are tested, the sex of the carrier and the particular chromosomes involved (Gropp \& Winking, 1981; Redi \& Capanna, 1988; Searle, 1993).

Our data on hybrids between karyotypic races of $S$. murinus show that litter size even in heterozygotes for five Rbs was no smaller than that in the less

\begin{tabular}{|c|c|cc|c|cc|cc|cc|cc|}
\hline \multicolumn{2}{|c|}{ Chromosome } & \multicolumn{2}{c|}{8.17} & 9.13 & 10.12 & 11.16 & \multicolumn{2}{|c|}{14.15} \\
\hline Rb-carrying parent & Sex of offspring & $\mathrm{Rb}$ & + & $\mathrm{Rb}$ & + & $\mathrm{Rb}$ & + & $\mathrm{Rb}$ & + & $\mathrm{Rb}$ & + \\
\hline \multirow{2}{*}{ Dam } & Females & 9 & 12 & 12 & 12 & 7 & 9 & 17 & 13 & 10 & 5 \\
& Males & 12 & 8 & 11 & 13 & 14 & 5 & 16 & 13 & 7 & 8 \\
\hline \multirow{2}{*}{ Sire } & Females & 12 & 25 & 19 & 22 & 12 & 9 & 10 & 10 & 22 & 22 \\
& Males & 25 & 16 & 15 & 21 & 9 & 4 & 2 & 9 & 16 & 21 \\
\hline
\end{tabular}

Fig. 2 Test for association between $\mathrm{Rbs}$ and sex in the progeny of dam and sire $\mathrm{Rb}$ heterozygotes crossed to shrews of standard karyotype $(+/+)$. Double border indicates the $2 \times 2$ table where the critical $\chi^{2}$ value was obtained $\left(\chi_{1}^{2}=5.26, P<0.05\right)$. However, after correction for multiple testing (Bonferroni test: Sokal \& Rohlf, 1995), this value fails to reach significance. 
Table 3 Mean litter sizes ( \pm SE) of crosses involving (a) the parental strains KAT and SRI and $\mathrm{F}_{1}$ hybrids and (b) later generation hybrids heterozygous for specific Rbs

\begin{tabular}{|c|c|c|c|c|}
\hline & Dam & Sire & $\begin{array}{l}\text { Number } \\
\text { of litters }\end{array}$ & Litter size \\
\hline \multirow[t]{8}{*}{ (a) } & KAT & KAT & 300 & $3.99 \pm 0.08$ \\
\hline & SRI & SRI & 97 & $2.33 \pm 0.08$ \\
\hline & SRI & KAT & 4 & $2.50 \pm 0.65$ \\
\hline & KAT & SRI & 15 & $2.67 \pm 0.30$ \\
\hline & $\mathrm{F}_{1}$ & $\mathrm{~F}_{1}$ & 14 & $2.21 \pm 0.33$ \\
\hline & KAT & $\mathrm{F}_{1}$ & 19 & $3.42 \pm 0.23$ \\
\hline & $\mathrm{F}_{1}$ & KAT & 30 & $2.88 \pm 0.20$ \\
\hline & $\mathrm{F}_{1}$ & SRI & 7 & $2.43 \pm 0.37$ \\
\hline \multirow[t]{12}{*}{ (b) } & $\mathrm{Rb}(8.17) /+$ & $+1+$ & 32 & $2.97 \pm 0.24$ \\
\hline & $\mathrm{Rb}(9.13) /+$ & $+/+$ & 31 & $2.97 \pm 0.21$ \\
\hline & $\mathrm{Rb}(10.12) /+$ & $+1+$ & 25 & $2.60 \pm 0.23$ \\
\hline & $\mathrm{Rb}(11.16) /+$ & $+1+$ & 40 & $2.65 \pm 0.17$ \\
\hline & $\mathrm{Rb}(14.15) /+$ & $+1+$ & 30 & $2.87 \pm 0.21$ \\
\hline & Total & & 158 & $2.81 \pm 0.09$ \\
\hline & $+1+$ & $\mathrm{Rb}(8.17) /+$ & 40 & $2.93+0.20$ \\
\hline & $+1+$ & $\mathrm{Rb}(9.13) /+$ & 37 & $3.05 \pm 0.23$ \\
\hline & $+1+$ & $\mathrm{Rb}(10.12) /+$ & 17 & $2.88 \pm 0.28$ \\
\hline & $+1+$ & $\mathrm{Rb}(11.16) /+$ & 17 & $2.82 \pm 0.30$ \\
\hline & $+/+$ & $\mathrm{Rb}(14.15) /+$ & 44 & $3.00 \pm 0.20$ \\
\hline & Total & & 155 & $2.96 \pm 0.10$ \\
\hline
\end{tabular}

fertile parental strain (SRI). We did not detect a strong effect of either heterozygosity for any of the Rbs, or the combined heterozygosity of both parents on the litter size. Even if Rb heterozygosity does affect litter size, its effect is not as strong as the effects of genetic background for the shrews that we examined. The same can be said for the influence of the SRI chromosome 7 variant in a heterozygous state.

There are clear differences in litter sizes between the KAT and SRI strains and also, unexpectedly, karyotypically homozygous males may influence litter size. Thus, crosses between KAT females and SRI males have significantly smaller litters than KAT $\times$ KAT crosses. The genetic basis of these strain effects is discussed by Aulchenko et al. (1998). In the present paper we are concentrating on the impact of chromosomal heterozygosity.

With regards the near-normal fertility of heterozygotes for Rbs or the variant chromosome 7 , it is reasonable to suggest that this does reflect orderly behaviour of heterozygous configurations at meiosis I. In an electron microscopic analysis of synaptonemal complexes at pachytene more than $90 \%$ of such configurations showed complete pairing without abnormality (Borodin et al., 1998).
Not only do heterozygotes for Rbs and the chromosomal 7 variant show near-normal fertility, their viability also appears to be similar to homozygotes. The pattern of segregation of each of the Rbs and the variant chromosome 7 in heterozygotes does not differ from Mendelian expectations.

The Mendelian segregation from heterozygotes also indicates that none of the rearrangements displays strong 'segregation distortion' either in males or females. However, our sample size, although not very small, was insufficient to detect weaker distortions. To detect a distortion of $5 \%$ a sample size of not less than 400 offspring would be needed. This is important, because it has been shown theoretically that even weak segregation distortion may significantly affect the probability of fixation of a chromosome variant (Hedrick, 1981).

Our studies also showed that all Rbs segregate independently of each other in the progeny of double heterozygotes and there was no convincing association between transmission of sex chromosomes and transmission of the Rbs.

Taken together, the data presented here greatly extend on our previous chromosome frequency analysis of the SK stock (Rogatcheva et al., 1997). The SK stock is the product of crosses between the 30-34 chromosome Sri Lanka race and the 40 chromosome standard race (represented by individuals that are derived from Nepal). We believe that crosses similar to these generated the polymorphism for three or more Rbs that is currently observed in Malaya (Sam et al., 1979). As first suggested by Yosida (1982), the Malay polymorphism appears to have arisen as a result of crosses between resident standard race shrews and Sri Lankan or South Indian shrews carrying Rbs accidentally brought over by humans in ships (Rogatcheva et al., 1997).

Given that we have shown that Rbs in S. murinus show little or no underdominance or segregation distortion, there is no reason to view the $\mathrm{Rb}$ polymorphism in Malaya as anything other than neutral variation. Further studies of the natural polymorphism would be valuable to test this null hypothesis further. In particular, it would be of interest to obtain more detailed information on population structure, and both within- and between-site data on frequency of the chromosomal variants. Such studies could help establish whether the chromosomal markers are varying in frequency by genetic drift (as expected under the null hypothesis) or whether there is any effect of selection.

Our studies on $S$. murinus echo those in a number of other species, most notably another shrew, Sorex 
araneus, for which it has proved difficult to demonstrate any infertility in $\mathrm{Rb}$ heterozygotes, even when several trivalents are expected at meiosis I (Searle, 1993). Given that infertility associated with chromosomal heterozygosity is important for 'chromosomal speciation' (King, 1993), these studies indicate that it may sometimes need very substantial Robertsonian differences between karyotypic races to promote speciation. In the common shrew, even hybrids between $\mathrm{Rb}$ races which form long-chain configurations at meiosis I may not be particularly unfit (Mercer et al., 1992).

With regards segregation of chromosomes from $\mathrm{Rb}$ heterozygotes, there are differences between Suncus murinus and Sorex araneus. Although we detected no segregation distortion in the first species, Wyttenbach \& Hausser (1996) found it in the second. It is of interest that $S$. araneus is more prone to form $\mathrm{Rb}$ races than $S$. murinus and this difference in segregation distortion, if general, may be important in race formation (cf. Hedrick, 1981).

The difference between Suncus murinus and Sorex araneus with regard to segregation distortion of Rbs indicates the need for individual studies to analyse particular chromosomal variants in particular species; extrapolating broadly is dangerous. This is as true for heterochromatic insertions as it is for Rbs. Whereas in S. murinus the chromosome 7 insertion does not segregate abnormally, in the house mouse a heterochromatic insertion of chromosome 1 can be associated with segregation distortion (Agulnik et al., 1990).

\section{Acknow ledgements}

This work was supported by research grants from the Ministry of Education, Science, Sport and Culture of Japan, INTAS (no. 93-1463) and the Russian Fund for Basic Researches (96-15-97738). M. B. R. was in receipt of a scholarship from Aichi Prefecture Government.

\section{References}

AGUlNiK, s. I., AGUlnik, A. I. AND RUVInSKY, A. O. 1990. Meiotic drive in female mice heterozygous for the HSR inserts on chromosome 1. Genet. Res., 55, 97-100.

AULCHENKO, Y. S., ODA, S.-I., ROGATCHEVA, M. B., BORODIN, P. M. AND AXENOVICH, T. I. 1998. Inheritance of litter size at birth in the house musk shrew (Suncus murinus, Insectivora, Soricidae). Genet. Res., 71 65-72.

BIDAU, C. J., BELINCO, C., MIROL., P. M. AND TOSTO, D. S. 1991. The complex Robertsonian system of Dichroplus pratensis (Melanoplinae, Acrididae). I. Geographical distribution of fusion polymorphisms. Génét. Sél. Évol., 23, 353-370.

BLISS, C. I. 1967. Statistics in Biology. McGraw-Hill, New York.

BORODIN, P. M., ROGATCHEVA, M. B., ZHELEZOVA, A. I. AND ODA, S.-I. 1998. Chromosome pairing in inter-racial hybrids of the house musk shrew (Suncus murinus, Insectivora, Soricidae). Genome, 41, 79-90.

BOUÉ, A. AND BOUÉ, J. 1981. Chromosome structural rearrangements and reproductive failure. Chromosomes Today, 7, 281-290.

GRAFODATSKy, A. S. AND RADJABLI, s. I. 1988. Chromosomes of Farm and Laboratory Animals. Nauka, Novosibirsk.

GROPP, A. AND WINKING, H. 1981. Robertsonian translocations: cytology, meiosis, segregation patterns and biological consequences of heterozygosity. Symp. Zool. Soc. Lond., 47, 141-181.

HEDRICK, P. W. 1981. The establishment of chromosomal variants. Evolution, 35, 322-332.

HUTTERER, R. 1993. Suncus murinus (Linnaeus, 1766). In: Wilson, D. E. and Reeder, D. M. (eds) Mammal Species of the World: A Taxonomic and Geographic Reference, $\mathrm{p}$. 103. Smithsonian Institution, Washington, DC.

ISHIKAWA, A., AKADAMA, I., NAMIKAWA, T. AND ODA, S. 1989. Development of a laboratory line (SRI line) derived from the wild house musk shrew, Suncus murinus, indigenous to Sri Lanka. Exp. Anim., 38, 231-237.

KING, M. 1993. Species Evolution: the Role of Chromosome Change. Cambridge University Press, Cambridge.

MerCer, S. J., WALlaCe, B. M. N. AND SEARLE, J. B. 1992. Male common shrews (Sorex araneus) with long meiotic chain configurations can be fertile: implications for chromosomal models of speciation. Cytogenet. Cell Genet., 60, 68-73.

ODA, S., KOYASU, K. AND SHRESTHA, K. C. 1992. Breeding of the house musk shrew, Suncus murinus originating from a wild population in Katmandu, Nepal. Ann. Res. Inst. Environ. Med., 43, 239-240.

REDI, C. A. AND CAPANNA, E. 1988. Robertsonian heterozygotes in the house mouse and the fate of their germ cells. In: Daniel, A. (ed.) The Cytogenetics of Mammalian Autosomal Rearrangements, pp. 315-359. Alan R. Liss, New York.

ROGATCHEVA, M. B., BORODIN, P. M., MATSUDA, Y. AND ODA, s. 1996. Standard karyotype of the house musk shrew, Suncus murinus (Insectivora, Soricidae). Cytologia, 61, 197-208.

ROGATCHEVA, M. B., BORODIN, P. M., ODA, S.-I. AND SEARLE, J. B. 1997. Robertsonian chromosomal variation in the house musk shrew (Suncus murinus, Insectivora, Soricidae) and the colonisation history of the species. Genome, 40, 18-24.

SAGE, R. D., ATChley, w. R. AND CAPANNA, E. 1993. House mice as models in systematic biology. Syst. Biol., 42, $523-561$.

(C) The Genetical Society of Great Britain, Heredity, 81, 335-341. 
SAM, C. H., YONG, H. S. AND DHALIWAL, s. s. 1979. The Gand C-bands in relation to Robertsonian polymorphism in the Malayan house shrew, Suncus murinus (Mammalia, Insectivora). Caryologia, 32, 355-363.

SEABRIGHT, M. 1971. A rapid banding technique for human chromosomes. Lancet, ii, 971-972.

SEARle, J. B. 1993. Chromosomal hybrid zones in eutherian mammals. In: Harrison R. G. (ed.) Hybrid Zones and the Evolutionary Process, pp. 309-353. Oxford University Press, New York.
SOKAL, R. R. AND ROHLF, F. J. 1995. Biometry, 3rd edn. Freeman, New York.

WYTTENBACH, A. AND HAUSSER, J. 1996. The fixation of metacentric chromosomes during chromosomal evolution in the common shrew (Sorex araneus, Insectivora). Hereditas, 125, 209-217.

YOSIDA, T. H. 1982. Cytogenetical studies on Insectivora. II. Geographical variation of chromosomes in the house shrew, Suncus murinus (Soricidae), in East, Southeast and Southwest Asia, with a note on the karyotype evolution and distribution. Jap. J. Genet., 57, 101-111. 